\title{
Sexual Communication and its Reflection on Satisfaction of Married Women I.Younis ${ }^{1}$, S.Ezzat ${ }^{1}$ and M.K.Abdelfattah ${ }^{2}$ \\ ${ }^{1}$ Dermatology \& Andrology, Dept., Faculty of Medicine, Benha Univ., Benha, Egypt \\ ${ }^{2}$ Dermatology \& Andrology, Dept., Faculty of Medicine, Zagazig Univ, Zagazig, Egypt \\ E-Mail:May11@gmail.com
}

\begin{abstract}
Couples prefer to avoid direct sexual communication, despite the fact that research shows that it is critical to healthy sexual interactions. We want to see whether there's a link between having good sexual communication with your spouse and having good sexual pleasure in your marriage. A self-filling online questionnaire that was disseminated through social media was utilised as a method. written in English and then into Arabic so that everyone can understand it, no matter what their educational background is. Questions on sexual activity, communication, and satisfaction were all included in the survey. Epidemiological statistics were also collected. The majority of participants were between the ages of 30 and 39. (73.8 percent ). In addition, the majority of them have a university degree (97.8 percent ). Eighty-four percent of them were city dwellers, and the majority of them had been married for six to ten years (46.9 percent ). The majority of individuals are content with their current sexual situation (63.1 percent ). Eightysix percent of women who said they were sexually happy said their husbands ensured they had orgasm. Sixty-four percent of those who were pleased stated it was easy to talk about their sexual wants and dreams with others. The pleased group had a confidence in their bodies that was 76.7 percent. Conclusion: In intimate partnerships, better sexual communication is linked to more sexual pleasure. Increasing the sexual happiness of women in marriage requires encouraging them to talk openly about their sexual wants, preferences, concerns, and dreams with their partners.
\end{abstract}

Keywords: Sexual, Communication, Satisfaction, Married, Women.

\section{Introduction}

When it comes to defining sexual communication, it's important to look at how much information is shared during the conversation, how good it is, and how often it occurs. Disclosing one's sexual preferences and willingness to participate in particular sexual acts is part of the sexual self-disclosure process. Other topics covered include sexual values, previous experiences, and sexual attitudes.

Open sexual communication has shown to be an important part of sexual interactions, although couples prefer to avoid direct sexual communication while in a relationship. Despite the fact that long-term relationships are certain to have ups and downs, it is very uncommon for the female partner to avoid addressing parts of the sexual connection with which they are dissatisfied for fear of their spouse becoming furious. Rather of talking about a partner's particular wants or preferences, people tend to make assumptions about a partner's preferences for foreplay and intercourse based on sexual stereotypes (i.e., what they think males typically seek). As a result, these estimates are often incorrect [2].

It is possible that doctors and academics are overlooking a key element in treating sexual diseases like female anorgasmia and enhancing sexual relationships by not paying attention to couples' sexual communication. In an analysis of theoretical theories for the genesis and maintenance of anorgasmia, it was found that communication impairments, a lack of trust in communication, and communication inhibitions are all linked to the disease.

Depending on the culture, a woman's capacity to talk openly about sexuality may be different from her ability to talk openly about other topics, including motherhood or sexual education. It's possible that the dynamics of family of origin or religion around sexual communication influence whether or not sexual conversation is promoted. Gender norms around sex may lead to a number of assumptions about who initiates and receives pleasure from sex.

We want to see whether there's a link between having good sexual communication with your spouse and having good sexual pleasure in your marriage.

\section{Patients and methods}

This cross section study from February 2020 to December 2020. The tool of this study is a self-report questionnaire written in English and translated into Arabic to esure it is understood by all subjects regardless their level of education. It was distributed on 468 women on social media and was fully filled anonymously by only 401 through the following link bit.ly/2m88cmp. The work started after obtaining approval of the ethical committee and department of dermatology and andrology at Benha faculty of medicine. The aim of the study and details of the questionnaire were explained to the women before taking their informed consent.

\section{Inclusion criteria}

- Married women with regular sexual activity.

- Women should be free from diseases known to affect sexual functions.

- Women should be able to read, write and have access to social media to be able to fill the questionnaire.

\section{Exclusion criteria}

- Women not currently participating in regular sexual intercourse e.g divorced or widowed

- Subjects refusing to cooperate. 
- Presence of other medical conditions affecting sexuality such as diabetes or receiving drugs that affect sexuality such as antihypertensive drugs.

- Presence of mental or psychiatric disorders.

The questionnaire included the following items:

- Epidemiological data : Age, Education level (reads and writes, finished secondary school or university degree), Residence (village, city or town) and duration of marriage.

- Questions to assess sexual activity: coital frequency and masturbation

- Questions to assess aspects of sexual satisfaction : satisfaction with coital frequency, wanting more or wanting less ,how often she reaches orgasm, satisfaction with sex life.

- Questions to assess communication : if she initiates intercourse or not, method of initiation, reasons why she wouldn't initiate, if her husband makes sure she reaches orgasm or not, if she verbally communicates with her husband during intercourse, if she ever fakes orgasm, the reasons for faking orgasm, response when her husband asked for intercourse in an inconvenient time, sharing fantasies and needs with husband or not and confidence in body image.

\subsection{Statistical analysis}

Data were collected, revised, coded and entered to the statistical package for Social Sciences (IBM SPSS) version 23. The Qualitative variables were presented as numbers and percentages. The comparison between groups with qualitative data were done by using Chisquare test and Fisher exact test instead of the Chisquare only when the expected count in any cell found less than 5. The confidence interval was set to $95 \%$ and the margin of error accepted was set to $5 \%$. So, the p-value was considered significant as the

Table (1) Demographic data. following: $\mathrm{P}>0.05$ : Non significant $(\mathrm{NS}), \mathrm{P}<0.05$ : Significant (S), $\mathrm{P}<0.01$ Highly significant (HS)

\section{Results}

The total number of participants is 401. Most of them belonged to age group 30-39 (73.8\%). Also, most of them finished university (97.8\%). Most of them lived in a city $(84.8 \%)$ and most of them have been married for 6-10 years $(46.9 \%)$ table (1)

Among participants $38.2 \%$ reach orgasm in less than $50 \%$ of the times they have intercourse, while $25.9 \%$ reaches orgasm almost every time and $(0.2 \%)$ never or rarely reaches orgasm. The majority are satisfied with the coital frequency $68.3 \%$, While the majority of those who are not satisfied want to have more frequent intercourse $85 \%$. Most of the participants are satisfied with their sex life $63.1 \%$ and $67.6 \%$ are not satisfied with their sex life blame their husbands Table (2).

Most of the participants initiate intercourse $(67.6 \%)$ when they want to. The most common method of initiation is giving signs and waiting for partner to start $(38.7 \%)$. $59.9 \%$ of the partipicants who do not initiate sex with their spouses stated that the reason is being shy. Most of the participants said that their husbands made sure they reached orgasm (76.6\%). Also, $63.1 \%$ of the participants stated that they fake orgasm "Sometimes".The most common reason for faking orgasm is to satisfy the partner $73.0 \%$. Among the participants $71.3 \%$ communicate verbally with their partners during intercourse. The majority of the participants $46.6 \%$ said that they apologized and explained their reasons when they wanted to decline intercourse. Also, most of them $55.4 \%$ said they were comfortable discussing their sexual desires and fantasies with their partners and $72.6 \%$ of them felt confident about their bodies. Table (3).

\begin{tabular}{lccc}
\hline Demographic data & n & \% \\
\hline & Age<20 & 1 & 0.2 \\
Age & Age 20-29 & 66 & 16.5 \\
& Age 30-39 & 296 & 73.8 \\
& Age 40-50 & 36 & 9.0 \\
Educational level & $50+$ & 2 & 0.5 \\
& Can only read \& write & 4 & 1.0 \\
& Finished 2ry school & 5 & 1.2 \\
Residence & Finished university & 392 & 97.8 \\
& City & 340 & 84.8 \\
& Town & 26 & 6.5 \\
How long have you been & Village & 35 & 8.7 \\
married? & 1 year & 20 & 5.0 \\
& $1-5$ years & 101 & 25.2 \\
& $6-10$ years & 188 & 46.9 \\
& $11-15$ years & 64 & 16.0 \\
\hline
\end{tabular}


Table (2) Sexual satisfaction.

\begin{tabular}{lccc}
\hline Sexual satisfaction & & n & \% \\
\hline How often do you reach & Almost always & 104 & 25.9 \\
orgasm? & In > 50\% of the times & 143 & 35.7 \\
& In <50\% of the times & 153 & 38.2 \\
Are you satisfied with this coital & Rarely or almost never & 1 & 0.2 \\
frequency? & Yes & 274 & 68.3 \\
If the answer to the previous & No & 127 & 31.7 \\
question is no & I want more & 108 & 85.0 \\
Are you satisfied with you sex & I want less & 19 & 15.0 \\
life? & Yes & 253 & 63.1 \\
If the answer is No Do you & No & 148 & 36.9 \\
blame your husband for it? & Yes & 100 & 67.6 \\
\hline
\end{tabular}

Table (3) Sexual communication

\begin{tabular}{|c|c|c|c|}
\hline & & $\mathbf{n}$ & $\%$ \\
\hline \multirow{2}{*}{$\begin{array}{l}\text { Do you ask/initiate sexual } \\
\text { intercourse with your husband } \\
\text { when you want to? }\end{array}$} & Yes & 271 & 67.6 \\
\hline & No & 130 & 32.4 \\
\hline \multirow{4}{*}{$\begin{array}{l}\text { If the answer is yes how do you } \\
\text { initiate? }\end{array}$} & Ask verbally & 95 & 35.1 \\
\hline & Give him signs and wait for him to start & 105 & 38.7 \\
\hline & Dress in a certain way to seduce him & 71 & 26.2 \\
\hline & $\begin{array}{c}\text { Your husband doesn't like you to ask for sexual } \\
\text { intercourse }\end{array}$ & 9 & 6.9 \\
\hline \multirow{3}{*}{$\begin{array}{l}\text { If the answer of question number } 8 \\
\text { is No, please clarify the reason }\end{array}$} & You are shy & 77 & 59.2 \\
\hline & $\begin{array}{l}\text { You think it is inappropriate for a female to ask for sexual } \\
\text { intercourse }\end{array}$ & 15 & 11.5 \\
\hline & You are afraid of being rejected by your husband & 29 & 22.3 \\
\hline \multirow{5}{*}{$\begin{array}{l}\text { Does your husband make sure you } \\
\text { reach orgasm? } \\
\text { Do you communicate with you } \\
\text { husband verbally during } \\
\text { intercourse? }\end{array}$} & Yes & 307 & 76.6 \\
\hline & No & 94 & 23.4 \\
\hline & Yes & 286 & 71.3 \\
\hline & No & 115 & 28.7 \\
\hline & Never & 112 & 27.9 \\
\hline \multirow[t]{3}{*}{ Do you ever fake orgasm? } & Sometimes & 253 & 63.1 \\
\hline & Always & 36 & 9.0 \\
\hline & To end the sexual intercourse quickly & 60 & 20.8 \\
\hline \multirow[t]{2}{*}{ If yes then why? } & To satisfy your partner & 211 & 73.0 \\
\hline & Because intercourse is painful for you & 18 & 6.2 \\
\hline If your husband asks for sexual & You agree against your will & 129 & 32.2 \\
\hline intercourse and you are not ready & You pretend to be busy or sleeping & 85 & 21.2 \\
\hline for it & You apologize and explain your reasons & 187 & 46.6 \\
\hline $\begin{array}{l}\text { How comfortable do you feel about } \\
\text { discussing your sexual }\end{array}$ & I can talk to him about anything & 222 & 55.4 \\
\hline $\begin{array}{l}\text { needs/fantasies/problems with } \\
\text { your husband? }\end{array}$ & I don't feel comfortable talking about it with him & 179 & 44.6 \\
\hline Do you feel confident about your & Yes & 291 & 72.6 \\
\hline body in front of your husband? & No & 110 & 27.4 \\
\hline
\end{tabular}

Among the younger age group $<20-2980.6 \%$ stated that their husbands made sure they reached orgasm compared to $60.5 \%$ of the older age group $(<40-50)$. Also, $23.7 \%$ of the older age group $<45-50$ reported always faking orgasm while only $11.9 \%$ of the younger age group $<20-29$ always fake orgasm. Fig. (1) 


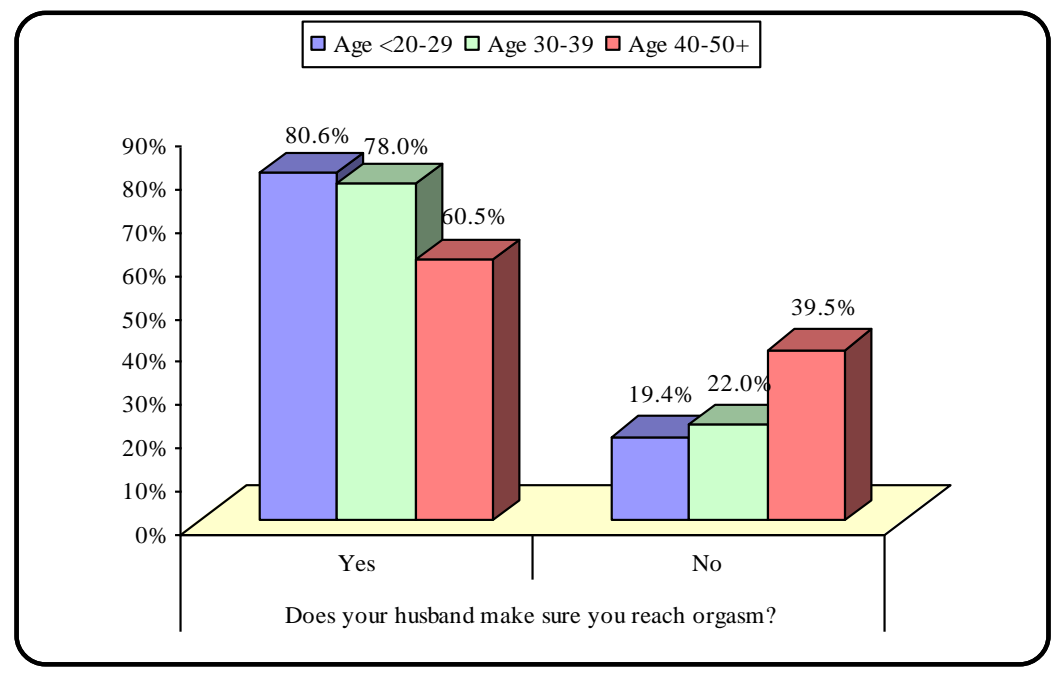

Fig. (1) Husband making sure that partner reaches orgasm among participants of different age groups

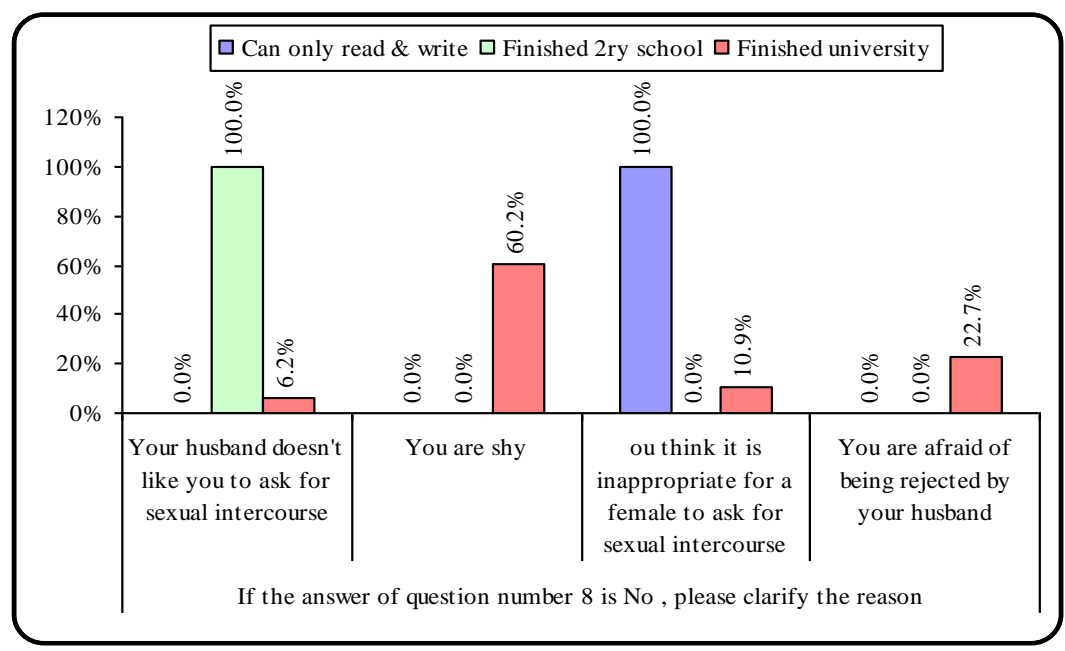

Fig. ( 2) Reasons for not initiating intercourse among participants of different educational backgrounds.

$77.5 \%$ of the participants who had university degree stated that their husband made sure they reached orgasm. Fig. (2)

In our study, $75.9 \%$ of those who are satisfied with their sex life stated they initiated sexual intercourse when they wanted to compared to only $24.1 \%$ of those who are not satisfied with their sex lives. The relation is highly statistically significant. $73.8 \%$ of those who don't initiate among the satisfied stated that the reason was due to being shy, while among the dissatisfied group $46.6 \%$ stated the reason in being shy and $33.3 \%$ said that fear of rejection by the husband was the reason. Among the satisfied group $86.2 \%$ stated their husbands made sure they reached orgasm vs $60.1 \%$ of the dissatisfied group. Results are highly significant. $81.0 \%$ of the satisfied group said they communicated verbally with their husbands during intercourse vs $54.7 \%$ of the dissatisfied group. Results are highly significant. $40.32 \%$ of the satisfied group stated they never faked orgasm, $55.34 \%$ said they sometimes did and only $4.35 \%$ said they always faked orgasm, Meanwhile among the dissatisfied group $6.76 \%$ stated they never faked orgasm, $76.35 \%$ stated they sometimes do and $16.89 \%$ said they always faked orgasm. Results are highly significant. $51.8 \%$ of the satisfied group stated that when they were not ready for intercourse they were honest and explained their reasons, $29.6 \%$ agreed against their will and $18.6 \%$ pretended to be busy or sleeping. While among the dissatisfied group $37.8 \%$ explained their reasons, $36.5 \%$ agreed against their will and $25.7 \%$ pretended to be busy or sleeping. the results are significant. $64.4 \%$ of the satisfied group said they felt comfortable discussing their sexual needs and fantasies vs $39.9 \%$ among the dissatisfied group. Results are highly significant. $76.7 \%$ of the satisfied group felt confident about their bodies in front of their husbands vs $65.5 \%$ among the dissatisfied group. Results are significant. Table (4) 
Table (4) Relationship between sexual satisfaction and aspects of communication

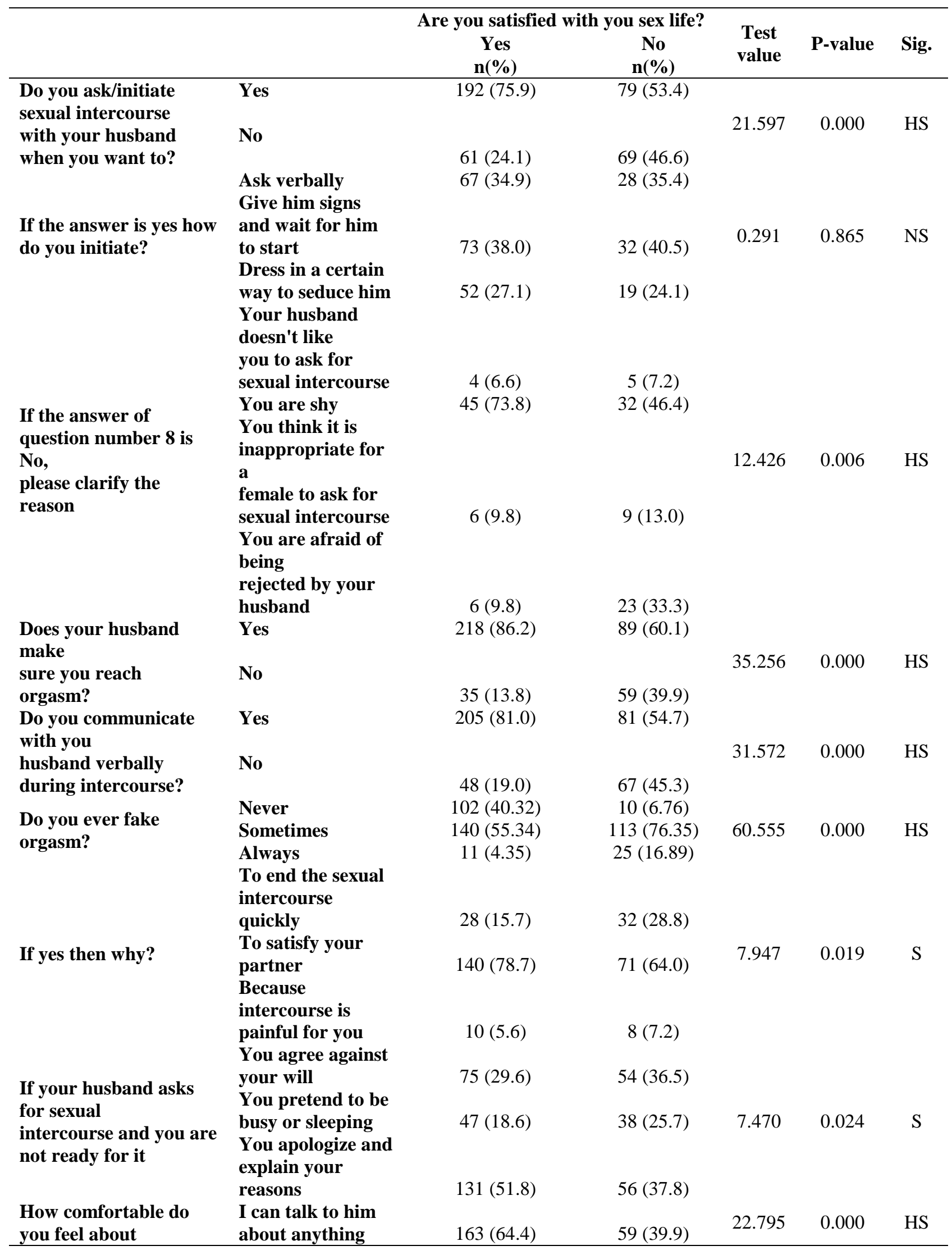




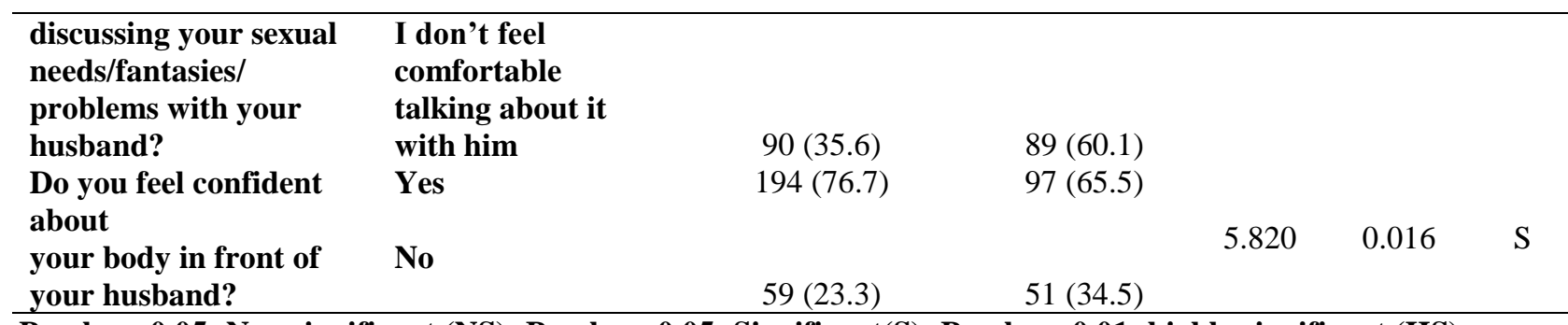

P-value >0.05: Non significant (NS); P-value <0.05: Significant(S); P-value< 0.01: highly significant (HS)

*:Chi-square test

\section{Discussion}

The importance of communication during a sexual encounter has been largely ignored in the scientific literature. Eighty-one percent of those polled said they exchanged verbal cues with their partners while having sex. The findings are comparable to those of Blunt-Vinti et al. [5], who showed that (a) more communication during sex leads to higher pleasure with sexual communication and (b) contentment with sexual communication predicts sexual satisfaction.

Among the pleased, $29.6 \%$ indicated they would agree against their will to participate in unwelcome sexual behaviour, compared to $36.5 \%$ of the unsatisfied group who said they would consent against their will as another way to gauge communication.

Consensual undesired sex or compliant sexual conduct [6] refers to sexual behaviour that is freely and voluntarily engaged in in spite of the consequences. There was more of a disparity between the two groups of those who claim they voluntarily participate in unwanted sexual behaviour, even though the findings are statistically significant nevertheless.

If a relationship doesn't work out, women tend to put the blame on themselves. Some women may think that giving their spouse with the sexual closeness they want is the greatest way to keep their relationship strong. There were almost twice as many women (32 percent) as males (17 percent) who participated in unwanted petting or intercourse because they were worried their partner would end the relationship if they refused, according to a research by Impette et al. [6]. Females may be more prone than males to engage in inappropriate sexual behaviour because they may believe that males have a greater sexual desire.

Many individuals think that it is religiously prohibited for a woman to say no to her husband's sexual desires, thus this may have a religious component.

The sexually happy individuals stated they would communicate honestly with their spouses by rejecting and expressing their reasons for doing so, whereas the unsatisfied participants said they would lie and claim to be busy or sleeping instead. Researchers found that sexual assertiveness, as described by Azmoude et al. [8], is the capacity to refuse unwelcome sexual relationships and to have a sexual engagement that provides joy to one's sexual life. There's evidence to indicate that women with higher sexual selfconfidence have more satisfying relationships and are better equipped to cope with sexual dysfunction. Sexual communication requires a certain level of assertiveness.

Having the ability to communicate one's sexual desires and wants is an important part of sexual assertiveness, therefore we also asked Sixty-four percent of the individuals who were happy said they felt comfortable sharing their sexual dreams and wants with their spouses, compared to 39.9 percent of the unsatisfied group who said they felt uncomfortable discussing their demands.

Studies performed by Sayyadi and colleagues [9] found that sexual aggressiveness was associated with good emotions about one's partner. According to their results, sexual assertiveness has a strong positive correlation with good emotions about one's partner.

There is a strong connection between marital distraction, dysfunctional sexual attitudes, and sexual aggressiveness among married women, as shown in the work of Asadi et al. [10]. When it came to sexual assertiveness, researchers discovered an unfavourable correlation between the two variables.

When asked how confident women felt about their bodies in front of their spouses, $76.7 \%$ of the happy individuals stated they felt confident, compared to $65.5 \%$ of the unsatisfied participants.

The findings are in line with previous research. According to Lowery et al. [11], sexual effectiveness, sexual assertiveness, and sexual esteem all suffer when a person has a negative body image or unhappiness with a particular body area during sexual engagement.

Scientists studied 154 adult women aged 18 to 49 years old for information on their sexual pleasure, selfimage, and sexual functioning, and the findings were illuminating. It turns out that even when sexual functioning remains constant, women who have higher self-confidence in their bodies and have fewer distractions related to their bodies have more sexual satisfaction than women who have frequent distractions and struggle with their bodies' images, according to multiple regression analyses [12].

\section{Conclusion}

In intimate partnerships, better sexual communication is linked to better sexual pleasure. Women should be encouraged to discuss their sexuality, such as sexual desires, preferences, fears, and fantasies, with their spouses, risking rejection, potential discomfort, and traditional gender norms, in 
order to obtain greater sexual satisfaction and, as a result, greater relationship satisfaction.

\section{References}

[1] A. B. Mallory, A. M. Stanton, and A. B. Handy, "Couples' sexual communication and dimensions of sexual function: A metaanalysis," J. Sex Res., vol. 3, pp. 24-43, 2019.

[2] U. S. Rehman, D. Balan, S. Sutherland, and J. McNeil, "Understanding barriers to sexual communication," J. Soc. Pers. Relat., vol. 36, pp. 2605-2623, 2019.

[3] A. C. Jones, W. D. Robinson, and R. B. Seedall, "The role of sexual communication in couples' sexual outcomes: A dyadic path analysis," J. Marital Fam. Ther., vol. 44, no. 4, pp. 606-623, 2018.

[4] M. P. Kelly, D. S. Strassberg, and C. M. Turner, "Communication and associated relationship issues in female anorgasmia," J. Sex Marital Ther., vol. 30, pp. 263-276, 2004.

[5] H. Blunt-Vinti, K. N. Jozkowski, and M. Hunt, "Show or tell? Does verbal and/or nonverbal sexual communication matter for sexual satisfaction?," J. Sex Marital Ther., vol. 45, pp. 206-217, 2019.

[6] E. A. Impett and L. A. Peplau, "Why some women consent to unwanted sex with a dating partner: Insights from attachment theory," Psychol. Women Q., vol. 26, pp. 360-370, 2002.

[7] C. L. Muehlenhard and S. K. Shippee, "Men's and women's reports of pretending orgasm," J. Sex Res., vol. 47, pp. 552-567, 2010.

[8] E. Azmoude, M. Firoozi, E. S. Sahebzad, and N. Asgharipour, "Relationship between gender roles and sexual assertiveness in married women," Int. J. community based Nurs. midwifery, vol. 4, pp. 363, 2016.

[9] F. Sayyadi, N. Golmakani, M. Ebrahimi, and A. Saki, "The relationship between sexual assertiveness and positive feelings towards spouse in married women," J. Midwifery Reprod. Heal., vol. 6, pp. 1305-1310, 2018.

[10] M. Asadi, A. Shiralipour, A. M. Nazry, M. Miri, and S. Shayad, "The relationship between aggression and communicational belief with sexual assertiveness on women," ProcediaSocial Behav. Sci., vol. 15, pp. 922-926, 2011.

[11] S. E. Lowery ."Body image, self-esteem, and health-related behaviors among male and female first year college students," J. Coll. Stud. Dev., vol. 46, pp. 612-623, 2005.

[12] Y. Pujols, C. M. Meston, and B. N. Seal, "The association between sexual satisfaction and body image in women," J. Sex. Med., vol. 7, pp. 905-916, 2010. 